\title{
Review
}

\section{Fundamentals of comparative and intercultural philosophy}

\author{
Lin Ma and Jaap van Brakel \\ Albany: SUNY Press, 2016, xi + 420pp., \\ ISBN 978-1438460161
}

Contemporary Political Theory (2020) 19, S157-S160. https://doi.org/10.1057/s41296019-00313-3; published online 8 March 2019

Comparative philosophy is philosophy, as Wilhelm Halbfass once wrote, to the extent that it aims at self-understanding, including its own process and indeed its very possibility as an element of its subject matter. This ambitious book by Lin $\mathrm{Ma}$ and Jaap van Brakel is concerned with the necessary preconditions of intercultural philosophy, a concern that, though often included under the title of 'methodology,' is more fundamental than the particular methods we use to study culturally distinct philosophical traditions (p. 1). The authors want this account to apply to every crosscultural philosophical activity, including translation, interpretation, and comparison.

Ma and van Brakel start from scratch, focusing on the 'primordial stages' of interpretation between traditions with no shared cultural background and languages that are as different as possible, such as those from different language families. Assuming interpreters from one tradition know nothing of the language of the other tradition, how is understanding possible? Ma and Van Brakel's discussion is, to my knowledge, the most thorough and in-depth treatment of the foundations of intercultural (also known as 'comparative' or 'cross-cultural') philosophy published to date. Criticizing approaches to intercultural dialog that depend on human universals or the assumption of an ideal language, they argue for a Wittgenstein-inspired view that presupposes all the concepts at stake in this dialog to be family-resemblance concepts.

In the first chapter, they lay out their conception of philosophy and of language. They take a 'pragmatic and synthetic' approach to the question of how to define the word philosophy, arguing for an 'open and inclusive stance toward the wide range of definitions of philosophy' (p. 20). They also argue that intercultural studies have not taken enough account of the fact that different traditions use different languages, contending that language shapes and constrains philosophy, though not completely.

In chapter 2, they critique three versions of the 'ideal language paradigm,' that is, the notion that all natural languages can be understood in terms of a universal

(c) 2019 Springer Nature Limited. 1470-8914 Contemporary Political Theory Vol. 19, S2, S157-S160

www.palgrave.com/journals 
language that captures all the basic concepts found in each. They see this paradigm as a shared feature of the analytic, postmodern, and hermeneutic philosophical traditions. In chapter 3, they argue that both universalism and relativism are committed to the ideal language paradigm. In both these chapters, they criticize, on methodological grounds, attempts to establish a set of 'basic' features shared by members of all traditions, such as emotions or logical rules or color terms. They want to resist the view that there exists some 'essence' or 'core' that can act as a fixed point of reference for those who are translating across different cultural traditions (p. 96).

In chapter 4, they begin to argue for their own view. Drawing on Wittgenstein, they claim that all general concepts found in different human languages are familyresemblance concepts. Such concepts include those within Western and nonWestern traditions; concepts compared across traditions (such as English 'color' and Chinese yanse), including general ethical and philosophical categories (philosophy and Chinese zhexue); and also concepts like 'language' and 'family resemblance' itself. By contrast, they note that many scholars working in nonWestern traditions write in a 'categorical style' in which a concept 'is assumed to have a precise meaning, a determinate relation to other meanings, and a straightforward translation into English' (p. 97).

In chapter 5, they introduce the principle 'No Need to Speak the Same Language,' which they think is applicable to every manner of cross-cultural interpretation. The NNSSL-principle entails that all participants in the crosscultural exchange speak their own native language and make efforts to understand the others. It also means results of cross-cultural inquiry should be conveyed in every language involved in the comparison. While the authors acknowledge that the principle will 'almost always increase practical problems' (p. 121), they find it to be a moral imperative of intercultural philosophy.

In chapter 6, Ma and Van Brakel discuss different views about conceptual schemes associated with Davidson, Kuhn, Putnam, and Goodman. For their part, they think that there is 'no single overarching meta-conceptual scheme' (p. 165): that we use many different conceptual schemes at once, and that the comparison of similarities and differences will always rely on these numerous schemes. Conceptual schemes are grounded in our forms of life, or the 'complex of natural and cultural circumstances' (p. 169) that form the background from which we describe and interpret the world. Family resemblances between different forms of life form the basis of interpretation. In looking at diversity of forms of life, the authors write, 'There are many similarities, but no universals, no cores' (p. 177).

Having outlined the key elements of their approach, in chapter 7, the authors turn to a critical discussion of some different approaches to intercultural philosophy. They criticize these approaches for focusing on universals at the expense of differences (p. 200). In chapter 8, Ma and Van Brakel explain how the projection of Western 'universal' categories onto other traditions can distort our 
interpretations. Even comparative philosophers such as David L. Hall and Roger T. Ames, who stress the significant differences of Chinese philosophy, are taken to task for using terminology from Western traditions, such as pragmatism and process philosophy, to explain the uniqueness of thought in China (p. 217).

In chapter 9, Ma and Van Brakel defend what they call the 'XYZ' model of cross-cultural comparison, in which various groups of contemporary philosophers $\mathrm{Z}$ who are engaged with texts, traditions, or philosophers $\mathrm{X}$ and $\mathrm{Y}$, set up a dialog between $\mathrm{X}$ and $\mathrm{Y}$ that involves many different, overlapping dialogs between various subsets of $\mathrm{Z}$. Apart from understanding $\mathrm{X}$ and $\mathrm{Y}$, understanding or 'mutual attunement' also has to be reached between the various translators, interpreters, and commentators who make up Z. A main upshot of this model is that one 'is always interpreting abundant things at the same time' (p. 295).

Finally, in chapter 10, Ma and Van Brakel sum up what they see as the necessary preconditions for interpretation. These include the assumption that the other party is a human being; that all concepts are family-resemblance concepts; the NNSSLprinciple; and finally, the 'principle of mutual attunement' that incorporates both the principle of charity and the principle of humanity.

The authors draw on a wide range of resources. While they refer extensively to Heidegger and Wittgenstein, as well as Davidson, Habermas, Quine, and Putman, their discussion also incorporates thinkers and terms from Chinese and other nonWestern sources as resources for thinking about intercultural philosophy. To take one example, in one short section of their discussion the definition of philosophy at work in cross-cultural research (pp. 14-18), they discuss not only Heidegger and Derrida, but also Hu Shi, Feng Youlan, Mou Zongzan, Kwame Gyeke, Henry Odura Oreku, and Kwasi Wiredu, among others. The list of works cited takes up some thirty-five pages.

While the style of the book incorporates many interesting examples and draws on numerous traditions, this feature can occasionally be frustrating. Their overview of the different kinds of intercultural philosophy in Ch. 7, for instance, includes six pages of discussion of Heidegger's forays into cross-cultural philosophy; then several pages on interkulturelle Philosophie in Germany; then a discussion of 'ethnophilosophy' in Africa; then of Eske Møllgaard's characterization of the influence of analytic and Continental philosophy on American sinology; and then a section on variations of 'world philosophy' as exemplified by the work of Robert E. Allinson, Vincent Shen, and Jiyuan Yu. There is not much explanation of why the authors have focused on these sources in particular, or how this assortment of ideas and thinkers reflects available approaches to comparative philosophy.

In addition, one might be skeptical of their reliance on family-resemblance concepts, which may be criticized for going too far in the other direction in its critique of universals. The typical objection to the family-resemblance approach is 
that it leaves the application of a concept too unrestricted, since there is no mechanism for determining which family resemblances are essential and which are accidental. Comparative philosophers likewise have acknowledged that the broader our notion of philosophy and other related terms, the less meaning these concepts have. Some discussion of the possible limitations of the family-resemblance model of comparison would perhaps help round out the discussion.

Regardless of these criticisms, anyone interested in the foundations of comparative philosophy will find this book to be essential reading. Of all the recent works that have been written on the methodology of comparative philosophy, it is this one that best captures the complexity and difficulty of cross-cultural interpretation. When, in the final pages, the authors list a number of strategies for avoiding the distortions that they see as plaguing much of intercultural philosophy; their advice is specific, meaningful, and well-earned. The book is a major step forward in the self-understanding of comparative philosophy.

Publisher's Note Springer Nature remains neutral with regard to jurisdictional claims in published maps and institutional affiliations.

Tim Connolly

East Stroudsburg University, East Stroudsburg, PA 18301, USA tconnolly@esu.edu 